\title{
Complex Chronic Conditions in Pediatrics: Needs for A Level of Complexity Classification System
}

\author{
Elena Godoy-Molina*, Jose María Ruiz-Sánchez and Ana Cordón-Martínez \\ Department of Pediatrics. Hospital Regional University Carlos Haya. Malaga. Spain \\ *Corresponding author: Elena Godoy-Molina, Department of Pediatrics. Carlos Haya Regional University Hospital. \\ Malaga. Spain
}

\begin{tabular}{l}
\hline ARTICLE INFO \\
\hline Received: November 07, 2020 \\
Published: November 12, 2020 \\
\hline Citation: Elena Godoy-Molina, Jose María \\
Ruiz-Sánchez, Ana Cordón-Martínez. Com- \\
plex Chronic Conditions in Pediatrics: \\
Needs for A Level of Complexity Classi- \\
fication System. Biomed J Sci \& Tech Res \\
31(5)-2020. BJSTR. MS.ID.005169.
\end{tabular}

\begin{abstract}
Over the last years, pediatric illness has undergone a dramatic epidemiological change. Advances in diagnostics, surgical techniques or treatment have resulted in the increased survival of patients, not only suffering from acute diseases, but also of patients with chronic and, in many cases, complex illnesses. The identification and proper classification of these patients is the first step for designing new care strategies and the creation of individualized care plans focused both on the patients and their families. This article aims to review the concept of chronic complex chronic conditions in pediatrics and the different tools available for their identification and classification.
\end{abstract}

\section{Introduction}

Over the last years, pediatric illness has undergone a dramatic epidemiological change with an increased prevalence of children with complex chronic conditions or medically complex children. This group includes children who have a multisystem disease or marked functional impairment whose survival is increasing due to better and earlier diagnostics and improved treatments. The pediatric practice must respond to this change in the care scenario of the pediatric patient and offer a system that enables long-term continuity of care $[1,2]$. The first difficulty with regard to the assistance of the medically complex patient is their correct identification; even though this group presents some common characteristics (medical fragility, functional limitations usually severe and associated with technology dependence, polypharmacy, risk of frequent and prolonged hospitalizations or high resource utilization) there is no consensus definition capable of collecting the entire spectrum of pediatric patients with complex chronic conditions as there are considerable variations in needs, not only medical; but psychological, educational and social ones, between patients [1-4].

Current definitions defined the complex chronic condition as any medical condition expected to last at least 12 months, involving

either several organ systems or one organ system with sufficient severity to require special paediatric care and, probably, some period of hospitalization in a tertiary care center [5]. Subsequently, the Simon et al group tried to make a less general definition of the term by including different items to facilitate the identification of this kind of patients. Using this definition, a child with a complex chronic condition would be one with: significant chronic conditions involving two or more body systems and expected to last at least 12 months, which requires treatment for controlling the disease; the condition can be expected to be episodic or continuously debilitating, or can be progressive and associated with deteriorating health with a decreased life expectancy in adulthood or associated continuous dependence on technology for at least six months; patients suffering from a progressive onco-hematological disease or metastatic malignancies with affected life functions are also included in this group [6].

According to these definitions, different instruments have been designed to facilitate the detection of children with complex chronic conditions (Table 1) such as the chronic condition indicators, the pediatric complex condition classification system or the pediatric medical complexity algorithm. But, using these instruments, we found that, in many cases, the diagnosis determines if a condition 
is or is not considered as complex; not taking into account other variables such as the degree of functional impairment, psychological impact on the family or socio-economic problems $[3,4,7]$. So how can we design health policies, care plans or create specialized units for children with medical complexity when we do not even know how many children suffer a complex chronic condition in our country, city or hospital? Following these guidelines, we would consider that a patient suffering from cystic fibrosis fits within the definition of a child with medical complexity but the complexity of a particular chronic condition can vary over time because of different factors; so if the patient is stable, with preserved pulmonary function and not affected at the nutritional level, would it have the same degree of complexity as patient afflicted with cystic fibrosis with frequent

Table 1: Instruments to identify children with medical complexity. exacerbations and who is oxygen dependent? $[2,4,7]$. This leads us to understand that we need to identify not only the complex patient as complex; we must also try to catalog the degree of complexity; given that it will motivate changes in their care needs, being essential to perform a comprehensive and multidisciplinary approach to these patients and to develop personalized care plans that will facilitate individualized assistance to both the patients and their families [2,7-9]. Moreover, as the care of this kind of patients involved an important financial and psychological burden to the family; aspects as the economic situation, the need for psychological intervention among parents or the doctor-patient relationship should be taken in to account when evaluating the level of complexity $[2,3,9]$.

\begin{tabular}{|c|c|c|}
\hline Chronic Condition Indicators & Evaluates the presence of chronic pathology. & Not designed for complexity evaluation. \\
\hline $\begin{array}{c}\text { Pediatric Complex Condition Classification } \\
\text { system }\end{array}$ & $\begin{array}{c}\text { Classifies patients as complex or not complex. } \\
\text { Excludes low complexity diagnoses. }\end{array}$ & Not evaluate levels of complexity. \\
\hline Pediatric medical complexity algorithm & $\begin{array}{c}\text { Classifies patients as a patient with complex or } \\
\text { non-complex chronic disease. }\end{array}$ & $\begin{array}{c}\text { It does not include socio-economic factors or the } \\
\text { doctor-patient relationship. } \\
\text { It does not evaluate levels of complexity. }\end{array}$ \\
\hline Clinical risk groups & $\begin{array}{c}\text { Classifies pathology in groups. Higher groups } \\
\text { usually correspond with more complex patients. }\end{array}$ & $\begin{array}{c}\text { Not designed for the identification of complex } \\
\text { patients. Not useful for daily use. }\end{array}$ \\
\hline
\end{tabular}

We need to introduce a new perspective where we evaluate the complex pediatric patient by its necessities and by aspects having a direct impact on the children's quality of life, rather by its diagnostics or a mere list of functional impairments and, from this approach, try to develop instruments that help the clinicians recognize the multiple attributes of complexity in childhood because without them the development of strategies that provides better health care to these children and their families are bound to fail.

\section{References}

1. Agostiniani R, Nanni L, Langiano $\mathrm{T}$ (2014) Children with medical complexity: the change in the pediatric epidemiology. J Pediatr Neonatal Individ Med 3(2): e030230.

2. Cohen E, Kuo D, Agrawal R, Berry J, Bhagat S, et al. (2011) Children With Medical Complexity: An Emerging Population for Clinical and Research Initiatives. Pediatrics 127(3): 529-538.

3. Kuo D, Houtrow A (2016) Council on Children with Disabilities. Recognition and Management of Medical Complexity. Pediatrics 138(6): e20163021.

ISSN: 2574-1241

DOI: $10.26717 / B J S T R .2020 .31 .005169$

Elena Godoy-Molina. Biomed J Sci \& Tech Res

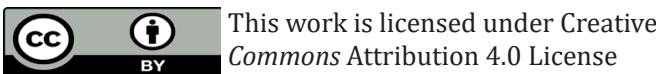

Submission Link: https://biomedres.us/submit-manuscript.php
4. Cohen E, Berry JG, Sanders L, Schor EL, Wise PH, et al. (2018) Status Complexicus? The Emergence of Pediatric Complex Care. Pediatrics 141(3): S202-S211.

5. Feudtner C, Christakis D, Connell F (2000) Pediatric deaths attributable to complex chronic conditions: a population-based study of Washington State, 1980-1997. Pediatrics 106: 205-209.

6. Simon T, Cawthon M, Stanford S, Popalisk J, Lyons D, et al. (2014) Pediatric Medical Complexity Algorithm: A New Method to Stratify Children by Medical Complexity. Pediatrics 133(6): e1647-e1654.

7. Berry J, Hall M, Cohen E, O'Neill M, Feudtner C, et al. (2015) Ways to Identify Children with Medical Complexity and the Importance of Why. J Pediatr 167(2): 229-237.

8. Hofacer RD, Panatopoulos A, Vineyard J, Tivis R, Nguyen E, et al. (2019) Clinical Care Coordination in Medically Complex Pediatric Cases: Results from the National Survey of Children With Special Health Care Needs. Glob Pediatr Health 7(6): 2333794X19847911.

9. Pordes E, Gordon J, Sanders LM, Cohen E (2018) Models of Care Delivery for Children with Medical Complexity. Pediatrics 141(Suppl 3): S212-S223.

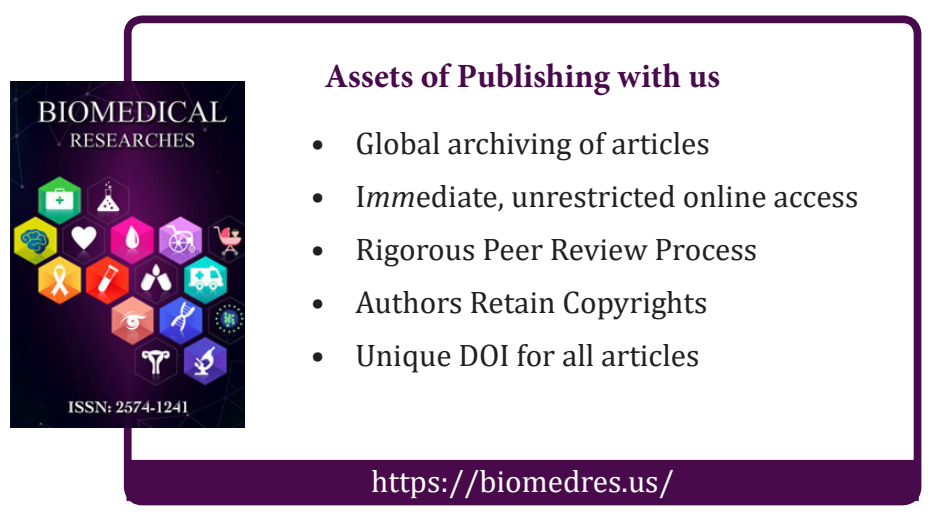

Copyright@ Elena Godoy-Molina | Biomed J Sci \& Tech Res | BJSTR. MS.ID.005169. 